\title{
Impacts of biological invasions: what's what and the way forward
}

\author{
Daniel Simberloff ${ }^{1}$, Jean-Louis Martin ${ }^{2}$, Piero Genovesi ${ }^{3}$, Virginie Maris ${ }^{2}$, \\ David A. Wardle ${ }^{4}$, James Aronson ${ }^{2,5}$, Franck Courchamp ${ }^{6}$, Bella Galil ${ }^{7}$, \\ Emili García-Berthou ${ }^{8}$, Michel Pascal ${ }^{9}$, Petr Pyšek ${ }^{10,11}$, Ronaldo Sousa ${ }^{12,13}$, \\ Eric Tabacchi ${ }^{14}$, and Montserrat Vilà ${ }^{15 *}$
}

\author{
${ }^{1}$ Department of Ecology and Evolutionary Biology, University of Tennessee, Knoxville, TN 37996, USA \\ ${ }^{2}$ CEFE-CNRS UMR5175, 1919 Route de Mende, 34293 Montpellier Cedex 5, France \\ ${ }^{3}$ Institute for Environmental Protection and Research and IUCN ISSG, Via Brancati 48, I-00144 Rome, Italy \\ ${ }^{4}$ Department of Forest Ecology and Management, Swedish University of Agricultural Sciences, SE901-83 Umeå, Sweden \\ ${ }^{5}$ Missouri Botanical Garden, 4344 Shaw Boulevard, St. Louis, MO 63110, USA \\ ${ }^{6}$ Laboratoire Ecologie, Systématique et Evolution, UMR CNRS 8079, Bat 362, Université Paris Sud, 91405 Orsay Cedex, France \\ ${ }^{7}$ IOLR, POB 8030, Haifa 31080, Israel \\ ${ }^{8}$ Institute of Aquatic Ecology, University of Girona, E-17071 Girona, Catalonia, Spain \\ ${ }^{9}$ INRA-UMR 0985, Campus de Beaulieu - Bâtiment 16, 35000 Rennes, France \\ ${ }^{10}$ Institute of Botany, Academy of Sciences of the Czech Republic, CZ-252 43 Průhonice, Czech Republic \\ ${ }^{11}$ Department of Ecology, Charles University Prague, Viničná 7, CZ-128 44 Prague, Czech Republic \\ ${ }^{12}$ CMEB, Centre of Molecular and Environmental Biology, Department of Biology, University of Minho, Campus de Gualtar, \\ 4710-057 Braga, Portugal \\ ${ }^{13}$ CIMAR-LA/CIIMAR - Centre of Marine and Environmental Research, Laboratory of Ecotoxicology and Ecology, \\ Rua dos Bragas 289, 4050-123 Porto, Portugal \\ ${ }^{14}$ Ecolab, UMR5245, CNRS-Université Paul Sabatier, Institut National Polytechnique, 118, Route de Narbonne, \\ 31062 Toulouse Cedex 9, France \\ ${ }^{15}$ Estación Biológica de Doñana, Centro Superior de Investigaciones Científicas (EBD-CSIC), C/Américo Vespucio s/n, \\ Isla de la Cartuja, E-41092 Sevilla, Spain
}

Study of the impacts of biological invasions, a pervasive component of global change, has generated remarkable understanding of the mechanisms and consequences of the spread of introduced populations. The growing field of invasion science, poised at a crossroads where ecology, social sciences, resource management, and public perception meet, is increasingly exposed to critical scrutiny from several perspectives. Although the rate of biological invasions, elucidation of their consequences, and knowledge about mitigation are growing rapidly, the very need for invasion science is disputed. Here, we highlight recent progress in understanding invasion impacts and management, and discuss the challenges that the discipline faces in its science and interactions with society.

Biological invasions: from asset to burden

Biological invasions are a pervasive global change [1,2], challenging the conservation of biodiversity and natural resources [3]. Recognition of this challenge fostered the growth of a new field (invasion science [4]) dedicated to detecting, understanding, and mitigating invasion impacts (see Glossary). Invasion research has shown that the scope

Corresponding author: Simberloff, D. (dsimberloff@utk.edu)

Keywords: biosecurity; community and ecosystem impact; eradication; long-term management; societal perception.

All authors fully contributed to the ideas and writing of the paper. Daniel Simberloff and Jean-Louis Martin initiated the project and workshop and coordinated the writing. and complexity of consequences greatly exceed earlier perceptions. Research continues to spawn technological improvements to deal with impacts [5,6], and invasion science underpins national and international regulatory frameworks protecting human health and economies [7].

Poised at a crossroads where ecology, social sciences, resource management, and economics meet, invasion science has been scrutinized from many perspectives, leading some to question the importance of invasion impacts and need for invasion science [8]. The field has also been challenged in its ability to interact with society, even being tagged as xenophobic [9]. These criticisms have cultural and historical contexts.

Public perception of introduced populations is cultureand organism-dependent [10]. Polynesians introduced rats for food, but others saw rats as a scourge on islands and

\section{Glossary}

Eradication: complete removal of all individuals of a distinct population, not contiguous with other populations.

Extirpation: elimination of a local population, but with conspecifics remaining in contiguous populations or nearby.

Impact: any significant change (increase or decrease) of an ecological property or process, regardless of perceived value to humans [16].

Introduced population: population that arrives at a site with intentional or accidental human assistance [4].

Invasive population: introduced population that spreads and maintains itself without human assistance [4].

Propagule pressure: the frequency with which a species is introduced to a site, combined with the number of individuals in each introduction event [82]. 
supported eradication programs. In Western societies, from the great explorations until the early 20th century, non-native species introduced by acclimatization societies were considered 'exotic' curiosities, often viewed as a resource [11]. Today, some still see many introduced populations as assets, because of aesthetic properties, popularity as ornamental plants and pets, or economic value. Certain non-natives, such as Eucalyptus in California, are so appreciated that they become cultural icons in their new ranges [12]. However, as both intentional and unintentional introductions increased throughout the 20th century, biologists gathered mounting evidence of the threat that some introductions pose for native species and ecosystems and for human well-being. This led to the launching of modern invasion science during the mid-1980s [13], a development that paralleled the rise of modern conservation biology and increasing public concern about biodiversity. Invasion scientists became increasingly predisposed against non-natives not because they originated elsewhere, but because the probability of negative impact by non-natives is far greater than for natives [14] and because the frequency of invasions has increased exponentially [15]. This, rather than displaced xenophobia, is why origins matter to invasion scientisits.

Here, we aim to: (i) depict the growing understanding of invasion impacts; (ii) show how scientists have responded to the increased management burden this understanding imposes; (iii) discuss challenges posed by the interaction of the field with society; and (iv) suggest ways to advance the field and enhance its ability to respond to challenges.

\section{A range of impacts: difficult to evaluate, uncertain, delayed, and pervasive Difficult to evaluate}

An ecological impact consists of any significant change in an ecological pattern or process [16]. Much popular literature and some scientific literature becloud invasion impacts and responses of species, communities, and ecosystems in two ways. First is the practice of designating native species as 'good' and introduced species as 'bad.' Species are neither and, furthermore, invasion pertains to the population level, not the species level. Different stakeholders can view an introduced population as 'harmful' or 'useful' [17]. When the Japanese tiger prawn Marsupenaeus japonicus, which is native to the Red Sea, reached the Mediterranean through the Suez Canal, fishermen applauded, but it extirpated a native prawn (Melicertus kerathurus), epitomizing 'harmful' for conservationists [18]. Second, invasion impacts have been labeled 'good' or 'bad' depending on the effect on a particular ecosystem service (e.g., [19]). An impact is 'good' or 'bad' only from certain perspectives. Schlaepfer et al. [19] have pointed to introduced populations aiding conservation - for instance, introduced trees providing nesting habitat for birds. However, a non-native plant population perceived as beneficial can actually attract native birds for nesting but ultimately decrease their survival or reproduction [20]. That nitrogen-fixing plants, disproportionately represented in non-native floras, enhance ecosystem nitrogen input, soil fertility, and productivity [21] is often seen as positive, but in oligotrophic systems it is commonly perceived as negative. Many cases of introduced populations aiding conservation involve negative effects on other species [22]. In several instances, an invader that has replaced natives substitutes as a resource for remaining natives. For example, introduced rats perform some pollination functions of the New Zealand birds that they helped eliminate [23].

Often, impacts usually seen as negative from the ecosystem perspective are perceived as positive by some societal segments. Invasion by Pinaceae throughout the southern hemisphere [24] usually reduces litter quality, impairs decomposition, and depletes many soil species [25], but the fast-growing trees support timber industries. Many invasive flammable grasses modify fire regimes and drive ecosystems to an alternative stable state [26] but may benefit livestock and so ranchers. Hence, the full range of ecological, economic, and sociological consequences should be considered when an invasion impact is evaluated.

\section{Uncertain but real and often delayed}

When a species is proposed for introduction or a recent introduction is detected, invasion science suggests cause for concern. In Europe, for example, even though only $11 \%$ of over 10000 non-native populations are known so far to cause measurable ecological impacts [27], this results in many problems. Among established aquatic species introduced to six European countries, 69\% have recognized ecological impacts [28]. These percentages are underestimates, because many impacts are subtle or in inaccessible habitat and so are characterized only after intensive study. Native species can also suddenly spread into new habitats, but the risk of ecologically harmful impacts is greatly elevated for non-natives: by a factor of 40 for plants of the USA, for example [14]. Furthermore, molecular methods increasingly reveal that what had been regarded as 'invasion' might instead result from new genotypes from distant sources [29]. Concern is also heightened because many introduced populations remain innocuous for extended periods before spreading and becoming invasive [30,31]. For instance, Brazilian pepper remained restricted in Florida for a century before rapidly expanding across a wide area [30], whereas plants introduced to Europe might take 150-400 years to reach their fullest areal extent [32].

\section{Pervasive from the population to the community and ecosystem levels}

Some population effects are obvious. Introduced terrestrial predators are often seen eating endemic island prey; although population consequences require careful study, we are unsurprised to learn these are dire. The same applies to introductions of predatory fish to lakes, which have caused both local extirpations and global extinctions of native fish and amphibians [33]. The growing roster of well-studied cases of such population impacts is enormous (e.g., [34]).

A recent finding is that certain extremely consequential impacts, particularly at the ecosystem level, are not readily detected. An example is the multiple effects of introduced nitrogen-fixers on ecosystem functions [35]. Although some impacts affecting entire communities and ecosystems have been recognized since at least the 1980s [35], more have 
Introduced herbivores

Gypsy moth (Lymantria dispar)

Hemlock woolly adelgid (Adelges tsugae)

Black-tailed deer (Odocoileus hemionus columbianus and red deer (Cervus elaphus)

North American beaver (Castor canadensis)

Rabbitfish (Siganus spp.)

Introduced predators

Yellow crazy ant (Anoplolepis gracilipes)

Ship rat (Rattus rattus), Norway rat (Rattus norvegicus), and Arctic fox (Vulpes lagopus)

Rainbow trout (Oncorhynchus mykiss)

Nile perch (Lates niloticus)

\section{Belowground invasions}

Root pathogenic fungi and oomycetes (notably Armillaria and Phytophthora spp.)

Earthworms

Predatory flatworm (Arthurdendyus triangulatus)

Invasive bivalves

Sphaeroma quoyanum (isopod)
Nutrient pulses to forest floor, altering soil organic matter dynamics

Hemlock replacement by species producing higher quality litter that stimulates nutrient cycling

Replacement of understory plants by plants producing poor-quality litter, altering nutrient cycling and the soil food web

Decline in understory vegetation dramatically reducing arthropods and songbirds

Change in watershed hydrology and nutrient cycling, transforming forests into meadows

Reduction of habitat complexity and species richness, and alteration of food webs

Dramatic reduction of red crab population, increasing tree seedling density, and reduction of litter decomposition

Predation on seabirds thwarting nutrient transfer from ocean to land. Rats change belowground community, nutrient cycling, and decomposition

Foxes change soil fertility and transform grasslands to shrub- and forb-dominated ecosystems

Usurping terrestrial insects falling into streams, causing native char to shift to foraging for insects feeding on bottom algae, increasing algal biomass, decreasing insect emergence and spider populations

Driving over 150 native fish species to extinction, including many phytoplanktivores and detritivores, favoring increased algal blooms and submersed vegetation, and massively increased prawn populations; perch fisheries attracted more humans, further exacerbating eutrophication

Causing massive tree death in Australia and California with wide-ranging impacts above- and belowground

In deglaciated parts of North America lacking native worms, causing loss of organic matter, nutrient mineralization, enhanced plant invasion, loss of rare native species, and altered soil invertebrate communities

In British islands and Faroe islands, depleting lumbricid earthworm populations, reducing soil porosity and drainage, increasing waterlogging, increasing domination by Juncus, and reducing mole density

Providing shelter and substrate, altering sediment chemistry, grain size, and organic matter content by sediment reworking, and increasing light penetration by filter feeding

In California, creating galleries that reduce sediment stability and increase erosion, ultimately converting saltmarshes to mudflats become apparent as invasion science has undergone a shift from a primary focus on impacts on particular species (e.g., endemic island birds devastated by introduced predators) to cumulative impacts on ecosystems [21].

Increasing emphasis on community and ecosystem impacts has revealed important, sometimes unsuspected, effects of introductions from all major trophic groups. For instance, many invasive plants transform ecosystems both above- and belowground, particularly when they differ in functional traits from native flora and when those traits drive ecosystem processes [36]. Although invasive plants frequently have traits more associated with rapid resource acquisition than those of natives [37], literature syntheses and meta-analyses often find no large or consistent overall differences between native and introduced plant populations in terms of functional traits [38] or effects on belowground processes $[39,40]$. This is because invasive plant effects depend not only on the types of invader, but also on characteristics of the invaded ecosystem [16].

A growing number of studies shows introduced consumers, such as herbivores, decomposers, and predators (Table 1), transforming community composition and ecosystem properties through trophic cascades and changed nutrient cycling. Some invasive consumers remove or add physical structures, altering erosion regimes and changing habitat suitability for other species [41]. Belowground, several invasive consumers also radically transform ecosystems (Table 1).

\section{A range of actions: prevention, eradication, and long- term management}

From caution to prevention

The litany of negative, far-reaching impacts of invasions suggests that proposed introductions warrant great caution. Greater efforts are needed to screen pathways and vectors that bring unintended introductions and to detect invaders quickly. By the time impacts are noted, irreversible changes might have occurred [42] or palliative measures might be too costly or impossible [43]. Guiding principles on invasive species adopted by the Convention on Biological Diversity (2002) reflect these findings: prevention is the priority response; early detection, rapid response, and possible eradication should follow when prevention fails. Long-term management is the last option. Statistics confirm the validity of this approach (Box 1, Figure 1). 


\section{Box 1. Costs and benefits: lessons from statistics}

Reducing propagule pressure pays: biosecurity in New Zealand and Australia

Stringent biosecurity based on risk assessment, as applied in New Zealand and Australia, has significantly reduced the number of invasions. Europe and New Zealand had similar invasion rates of non-native mammals through the 19th century, but no invasions occurred in New Zealand after public perceptions shifted and biosecurity policies were adopted (Figure I).

Rapid response versus procrastination for an invasive Pacific alga In both Europe and California, the invasive Pacific alga, Caulerpa taxifolia, was quickly detected in small patches. In California, a US\$7000 000 eradication effort mounted within 6 months of discovery succeeded in 2 years [96]. In the Mediterranean, procrastination for several years allowed the species to spread to thousands of hectares off the coasts of Spain, France, Monaco, Italy, Croatia, and Tunisia [97], and it is now ineradicable with current technology.

\section{Misleading headcount: the Hawaiian avifauna}

The Hawaiian Islands housed at least 114 native bird species, almost all endemic, before humans arrived approximately 1000 years ago. At least 56 of these species are now globally extinct [98]. Of 53 introduced bird species from five continents that established populations there [99], almost all are common in their native ranges and many are widely established elsewhere. Although local avian species number is almost unchanged, global avian biodiversity has been significantly reduced.

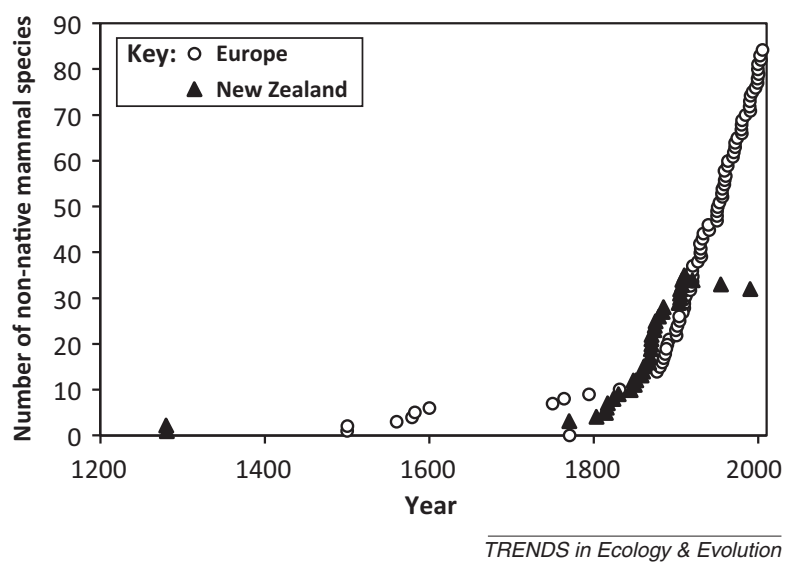

Figure I. Numbers of non-native mammal species established in Europe and New Zealand over eight centuries (compiled by P. Genovesi and M. Clout).

Prevention can occur at different stages, such as constricting pathways, intercepting movements at borders, and assessing risk for intentional imports. Improved ballast water treatment exemplifies pathway constriction. Mid-ocean ballast-water exchange for ships heading to freshwater ports can reduce freshwater zooplankton concentration in ship tanks by $99 \%$ [44]. Interception programs can reduce propagule pressure of potential invaders. In Europe between 1995 and 2004, over 80\% of the 302 intercepted non-native insect species were not established in Europe [45]. New Zealand has intercepted at least 27 non-native mosquito species, including important disease vectors [46]. Stringent biosecurity can bring huge economic benefits (Box 1). For instance, the Australian plant quarantine program provides savings by screening out putative invaders. Even after accounting for lost revenue from the few non-weeds that might be excluded, screening could

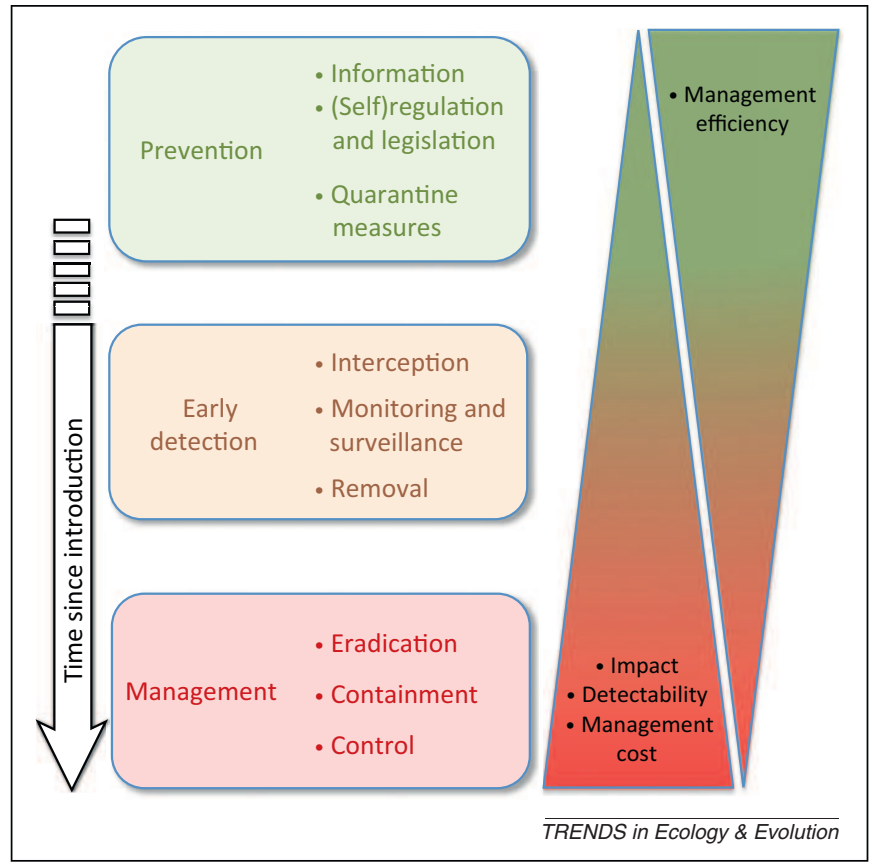

Figure 1. Management strategy against invasive species. The optimal strategy evolves with time since introduction, with management efficiency decreasing and management costs increasing with time since introduction.

save the Australian economy US $\$ 1.67$ billion over 50 years [47].

\section{From early action to eradication}

Whatever the prevention effort, some species enter any jurisdiction; it is important to detect them and respond quickly as such actions are decisive in preventing invasions $[48,49]$. Early detection can be improved by innovative tools, such as monitoring for environmental DNA [50]. Molecular approaches are increasingly used to monitor invasions in vulnerable environments [51]. Early detection allows for cost-effective removal. For introduced plants in New Zealand, early extirpation costs on average 40 times less than later attempts to extirpate widely established populations [52]. The contrast in timing of management between invasions of the Mediterranean and California by the alga Caulerpa taxifolia is telling (Box 1).

Prompt removal is also ecologically less risky than later interventions. Eradicating well-established invaders can cause surprises, such as release of another, previously suppressed non-native [53]. Thus, substantial research is required about the ecosystem role of a longstanding invader before eradication is attempted. This precaution does not apply to populations detected early, which will not have established strong interspecific relations within the invaded community.

Eradication technologies have improved dramatically. Of more than 1000 attempted eradications, $86 \%$ succeeded, including several long-standing invasions [54]. Avoidance of non-target effects has also improved [53]. Eradication can be cheaper than long-term management. For instance, 1 year of removing coypu (Myocastor coypus) in Italy would cost more than twice as much as the entire successful British eradication campaign [55]. Eradication increasingly helps threatened species recover. It has improved the 
Box 2. Carefully planned restoration improves invasion management: The Zena Forest Restoration Program

Zena Forest (Willamette Valley, Oregon) exemplifies restoration in the Pacific Northwest, where oak woodlands occupy interior valleys between the Coast and Cascade mountain ranges. Oregon white oak (Quercus garryana) is fire-adapted and grows in pure stands or with Douglas fir (Pseudotsuga menziesii), ponderosa pine (Pinus ponderosa), bigleaf maple (Acer macrophyllum), and other trees depending on site conditions and past timber exploitation. Oregon white oak is not shade-tolerant and, without fire, is overtopped by native Douglas fir and grand fir (Abies grandis), as well as by various introduced plants [100].

Part of Zena Forest (120 ha) was purchased in 2009 by Willamette University for restoration research and education. To restore oak savanna, most competing Douglas firs are removed or killed (and left as snags). All non-native cherry (Prunus spp.) are removed, along with other invaders (e.g., blackberry (Rubus sp.), scotch broom (Cytisus scoparius) and English hawthorn (Crateagus laevigata)). One goal is to identify 'legacy' oaks and clear competing trees, so that the oaks become wide crowned and have more wildlife value owing to larger acorn crops and development of cavities for small mammals and birds [100].

Young oak stands are thinned to 100-125 trees per ha. Invasive brush species are mechanically removed or treated with herbicides. Heavy mowing and prescribed burning reduce fuel loads and open areas for native grasses and wildflowers. Following reintroduced burning, seeds of native grasses and forbs are sown to restore native prairie. This is important because two butterfly species endangered in the Willamette Valley need these plants for food and reproduction. Ongoing monitoring and evaluation make this a valuable pilot site for similar restoration in the region.

Red List conservation status of 11 bird, five mammal, and one amphibian species [56]. However, reinvasion risk can remain high, necessitating ongoing monitoring and occasional intervention. Such costly programs might not be deemed high priorities unless they are part of broader programs aimed at maintaining biodiversity and sustainable resource use (Box 2).

\section{From long-term management to restoration}

For cases where eradication fails or is not attempted, longterm management has improved, with more ambitious targets than a mere decade ago. New technologies demonstrate that long-term management of invaders is neither futile nor necessarily damaging to non-targets. For example, a synthetic larval pheromone attracting anadromous adult sea lampreys is replacing barriers and lampricides in parts of the Great Lakes [57]. A 'Super Sucker' vacuum device enabled removal of two invasive algae from Hawaiian coral reefs [58]. 'BioBullets,' minute beads containing atomized potassium chloride coated with non-ionic surfactant, helped remove zebra mussels from UK water facilities [59].

When non-native populations have long been present, management is more complicated because costs tend to be greater, probability of success lower, and stakeholders might favor maintaining the invader. Examples of the complexities of their management include ship rats that affect seabirds of Mediterranean islands [60] and some agricultural weeds [61]. Decisions on managing longstanding populations must be case-specific and entail the best information on invasion impact, likelihood of success and recovery, management methods, and possible non-target impacts.
Removing or reducing an invader often does not suffice to re-establish native communities and ecosystems, and so active restoration can be crucial [62]. The many advances in restoration science are beyond the scope of this paper; Box 2 provides an example integrating invasion management with restoration.

\section{Challenges posed by how society perceives invasions}

An unresolved issue for managing invasions is articulating biodiversity conservation with other social concerns. Such concerns depend on how the public perceives a phenomenon, and perceptions are shaped by multiple factors of which scientific knowledge is only one. This underscores the need for invasion scientists to transfer knowledge effectively.

\section{Perception of non-native species: a multifaceted process} Perceptions by society of introduced species can change. For example, a century ago, citizens and government agencies collaborated to introduce deer to the Haida Gwaii archipelago (British Columbia, Canada) as a source of meat [63]. Today, government agencies consider deer a problem, and the local community increasingly deplores the impact of deer on vegetation $[63,64]$.

For the public to perceive an impact, a visible effect by a visible invader is usually critical. Impacts belowground or underwater are not as easily recognized as those aboveground. Landscapes overwhelmed by kudzu vines are striking, whereas disruption of soil organisms and processes by introduced earthworms did not attract significant attention until research revealed they can transform North American forests [65]. Similarly, direct threats to endangered endemic or charismatic species attract attention, whereas gradual changes in abundance and distribution of common species or ecological properties tend to pass unnoticed. Invasion scientists need to alert the public and policymakers to subtle or non-obvious impacts.

The appearance and reputation of the invader also matter, often independently of its impact. Plans to kill introduced ungulates (e.g., feral domestic animals such as horses in the USA, camels in Australia, or deer on islands) or charismatic species such as mute swans in North America or gray squirrels in Europe often encounter opposition from the public and from animal defenders, whereas campaigns against invertebrates face no such resistance.

\section{Communicating with society: a need for clarification}

New concepts, sometimes produced by science, can also influence public perception. For example, the suggestion that local biodiversity can be maintained or even enriched in the face of invasions [66] imparts a positive message that can lead to invasions being seen more as opportunities than as problems. So does the proposition that 'novel ecosystems' including non-native species can provide ecosystem services equivalent to those of nativedominated ecosystems [67]. The public does not necessarily perceive that maintenance of local biodiversity by virtue of invasions is often at the expense of global biodiversity (e.g., Box 1, Hawaiian avifauna) or that criteria for designating an ecosystem 'novel' have not 
been provided, and quantification of services such ecosystems provide has barely begun [68].

To conceptualize their research objects and to communicate with the public and land managers, invasion scientists, as do other scientists [69], developed metaphors. They have been accused of relying on a strongly normative, loaded vocabulary, borrowing military images [70] or worse, using xenophobic and racist expressions [71]. However, use of terms such as 'invasion' to emphasize the spread of many phenomena considered harmful is commonplace ( $c f$. metaphors used in public health and economics). In invasion science, as in other contexts, researchers talk about 'invasions' because what is observed really is reminiscent of armies moving. Media reports on biological invasions often attract readers' attention with military metaphors. However, invasion scientists, indeed all scientists, should beware of value-laden vocabulary to avoid the risk of sterile ideological arguments.

The charge of xenophobia, fear of strangers because of their origins, is of a different nature. As stated, populations of non-native species are not problematic because they are not native per se, but because they are more likely than natives to cause ecological damage. The recommendation to prevent introductions and to beware of newly established populations is consistent with the precautionary principle, which has complex ethical and social implications. It comes with incentives to kill organisms solely because of the 'potential' problems that they could pose. These can be sentient beings for which one might have ethical concerns [72]. It reduces people's freedom to keep non-native plants and animals. It also limits economic activities that can release invaders (e.g., horticulture or the pet trade). These costs are the price to be paid to avoid further devastating impacts on ecosystems and human well-being and increasing global homogenization of ecosystems. The wish to maintain the global diversity of native communities and ecosystems has nothing to do with xenophobia. On the contrary, it stems from principles similar to those that defend the right for every human society to retain its cultural distinctiveness, as proclaimed by the Council of Europe [73] and UNESCO [74].

\section{The way forward}

\section{From the obvious to the subtle and pervasive}

As a cross-disciplinary field linking with many other fields [6], invasion science will continue to provide important insights into areas as diverse as conservation biology, evolutionary biology, population ecology, ecosystem ecology, global change science, and restoration ecology. However, above all, invasion science will lead to improved understanding of how adding a single species to a community can greatly modify biodiversity and ecosystem functioning.

Invasion science must develop better metrics for quantifying and categorizing impacts $[16,27]$ to improve prioritization of management and risk assessments. Economists require such quantified information for valuing impacts and courses of action in the cost-benefit analyses of individual species that are a pillar of invasion economics [75]. Attempts to mitigate invasion impacts on ecosystems and services that they provide will have to account for the entire range of impacts and complexity of interspecific interactions. This will require invasion science to focus not only on loss of charismatic species globally, or changes in populations locally, but also on the consequences of invasions for regional diversity. These often pertain to the distribution and abundance of obscure community members, to changes in trophic networks that can affect ecosystem functioning, and to concepts such as diversity homogenization at the landscape scale. Few studies have focused on these subjects despite their potential importance to biodiversity conservation. This comprehensive approach remains the core of understanding and mitigating the consequences of biotic homogenization [76].

\section{From principles to applications: bridging the gaps}

Biosecurity policies and strategies must be updated regularly to reflect new findings [6]. Policies on invasions are in fact solidly based on science. The Convention on Biological Diversity (decision VI/23) incorporated findings of invasion science to define its guiding principles on invaders, ranking prevention, early detection and rapid response, and eradication as noted above. The same principles were again stressed by the G8 Environment in the Charter of Syracuse of 2009 and by leaders of the most influential world conservation organizations [77], who called for strengthening, not weakening, the struggle against invasions.

However, whereas key principles on how to respond to invasions are well advanced, their application remains limited. For management, the key challenge is to bridge the gap between growing scientific understanding of impacts and management action. This will require better integration of ecological perspectives and knowledge with socioeconomic considerations and human perceptions of invasions. For instance, most cost-benefit analyses simply attempt to detail costs and benefits of particular invasions post facto. Therefore, they do not encompass prevention, the preferred management strategy [75]; neither do they address the ongoing costs and benefits of different possible policy decisions regarding invasions in general (Courtois $\mathrm{P}$. Mulier C., and Salles, J-M. personal communication). Economists cannot advance in this direction without information from invasion scientists on the gamut of impacts and possible strategies to deal with them. With such knowledge, economists could then inform the public about economic consequences of various courses of action, just as ecologists inform them about ecological consequences, but it is the public and its policymakers who must define societal objectives and decide how to achieve them.

\section{From colliding worldviews to practical solutions}

Some controversies about invasion management are rooted in divergent ethical frameworks. Three main worldviews collide in a 'triangular affair' [78]. Ecocentrists focus on ecological entities or processes. They readily admit that invasions should be avoided and that, when it is feasible, invaders should be eradicated to protect biodiversity. Anthropocentrists believe only humans deserve direct moral consideration. They do not worry about ecological impacts of invasions unless these also drive economic or social damages. Zoocentrists accord equal moral consideration to every sentient being. They oppose sacrificing the 
interests of individual animals for the sake of human interests or biodiversity per se and have often opposed eradication plans. This triangle can be 'squared' by adding a fourth corner, surely under-represented, of biocentrists, who care for every individual living being, sentient or not. It would be vain for scientists to try to settle such a debate, but anyone engaged in invasion management should pay attention to these underlying ethical issues [72].

One way to proceed towards consensus and social agreement would be to acknowledge the legitimacy of these different ethical commitments and to try to overcome theoretical disagreements through collective search for practical solutions to problems related to specific invasions [79]. Indeed, what is shared by the three (or four) corners of the affair is a kind of absolutism regarding moral principles. However, real people in real life usually compromise among these poles depending on the specifics of situations. Moral concerns are more a collective elaboration of norms from the ground up than purely deductive applications of theoretical principles. By honestly and respectfully engaging in this debate, scientists and managers might not only influence public perceptions but also test and improve their own moral positions.

\section{Understanding invasions in a changing world}

Finally, two major challenges must be overcome related to how scientists and the public perceive introduced populations, their consequences, and their management. First is the need to shift attention further from dominant focus on the properties of invading organisms to how anthropogenic changes in ecosystems facilitate many invasions (e.g., $[62,80]$ but see [81]). Such a shift can lead to new ways to prevent invasions or to mitigate consequences of ongoing ones, for example through grazing or water management policies. Second is the need to convey information to the public about the range, scope, and consequences of less obvious effects of invasions, such as those affecting ecosystem processes. Scientists are also well positioned to elucidate the complexities of invasions and to explore realistic management options. Although most invasion scientists endorse a normative commitment towards biodiversity, their proper role as scientists, in terms of public discourse, is to educate citizens in a way that informs debate within society about how to think about and manage invasions.

\section{Acknowledgments}

The workshop that spawned this paper was sponsored by CEFE-CNRS, the University of Montpellier (UM2) and the Région Languedoc Roussillon. P.P. was supported by grant no. P504/11/1028 (Czech Science Foundation), long-term research development project no. RVO 67985939 (Academy of Sciences of the Czech Republic), institutional resources of Ministry of Education, Youth and Sports of the Czech Republic, and acknowledges the support by Praemium Academiae award from the Academy of Sciences of the Czech Republic. D.A.W. was supported by a Wallenberg Scholars award, E.G.B. by the Spanish Ministry of Science (projects CGL2009-12877-C02-01 and CSD200900065), M.V. by the Spanish Ministry of Science projects CGL2009-7515 and CSD2008-00040 and the Junta de Andalucía RNM-4031, and F.C. by the French ANR (2009 PEXT 010 01). We thank three anonymous reviewers for constructive comments, Jean-Michel Salles, Pierre Courtois, and Chloé Mulier for discussion, and Bérengère Merlot for assistance with references.

\section{References}

1 National Research Council (USA) (2000) Global Change Ecosystems Research, National Academy Press

2 Millennium Ecosystem Assessment (2005) Ecosystems and Human Well-Being: Current State and Trends: Findings of the Condition and Trends Working Group, Island Press

3 TEEB (2010) The Economics of Ecosystems and Biodiversity: Ecological and Economic Foundations, Earthscan

4 Richardson, D.M. (2011) Invasion science. The roads travelled and the roads ahead. In Fifty Years of Invasion Ecology: The Legacy of Charles Elton (Richardson, D.M., ed.), pp. 397-401, Blackwell Publishing

5 Asner, G.P.et al. (2008) Invasive plants transform the three-dimensional structure of rain forests. Proc. Natl. Acad. Sci. U.S.A. 105, 4519-4523

6 Pyšek, P. and Richardson, D.M. (2010) Invasive species, environmental change and management, and health. Annu. Rev. Environ. Resour. 35, 25-55

7 Hulme, P.E. et al. (2008) Grasping at the routes of biological invasions: a framework for integrating pathways into policy. J. Appl. Ecol. 45, 403-414

8 Davis, M.A. et al. (2011) Don't judge species on their origins. Nature 474, 153-154

9 Young, A.M. and Larson, B.M.H. (2011) Clarifying debates in invasion biology: a survey of invasion biologists. Environ. Res. 111, 893-898

10 Coates, P. (2007) American Perceptions of Immigrant and Invasive Species: Strangers on the Land, University of California Press

11 Gruvel, A. (1936) Contribution à l'étude de la bionomie générale et de l'exploitation de la faune du Canal de Suez. Mém. Inst. d'Égypte 29, 1229 (in French)

12 Nuñez, M.A. and Simberloff, D. (2005) Invasive species and the cultural keystone concept. Ecol. Soc. 10, r4

13 Simberloff, D. (2011) Charles Elton: neither founder nor siren, but prophet. In Fifty Years of Invasion Ecology: The Legacy of Charles Elton (Richardson, D.M., ed.), pp. 11-24, Blackwell Publishing

14 Simberloff, D. et al. (2012) The natives are restless, but not often and mostly when disturbed. Ecology 93, 598-607

15 Hulme, P.E. et al., eds (2009) Delivering Alien Invasive Species Inventories for Europe (DAISIE) Handbook of Alien Species in Europe, Springer

16 Pyšek, P. et al. (2012) A global assessment of alien invasive plant impacts on resident species, communities and ecosystems: the interaction of impact measures, invading species' traits and environment. Global Change Biol. 18, 1725-1737

17 Duffy, J.E. (2009) Why biodiversity is important to the functioning of real-world ecosystems. Front. Ecol. Environ. 7, 437-444

18 Galil, B.S. (2007) Loss or gain? Invasive aliens and biodiversity in the Mediterranean Sea. Mar. Pollut. Bull. 55, 314-322

19 Schlaepfer, M.A. et al. (2011) The potential conservation value of nonnative species. Conserv. Biol. 25, 428-437

20 Rodewald, A.D. (2012) Spreading messages about invasives. Divers. Distrib. 18, 97-99

21 Ehrenfeld, J.G. (2011) Ecosystem consequences of biological invasions. Annu. Rev. Ecol. Evol. Syst. 41, 59-80

22 Vitule, J.R.S. et al. Revisiting the conservation value of non-native species. Cons. Biol.(in press)

23 Pattemore, D.E. and Wilcove, D.S. (2012) Invasive rats and recent colonist birds partially compensate for the loss of endemic New Zealand pollinators. Proc. R. Soc. B 79, 1597-1605

24 Richardson, D.M. (2006) Pinus: a model group for unlocking the secrets of alien plant invasions? Preslia 78, 375-388

25 Dehlin, H. et al. (2008) Tree seedling performance and belowground properties in stands of invasive and native tree species. N.Z. J. Ecol. 32, 67-79

26 Mack, M.C. and D’Antonio, C.M. (1998) Impacts of biological invasions on disturbance regimes. Trends Ecol. Evol. 13, 195-198

27 Vilà, M. et al. (2010) How well do we understand the impacts of alien species on ecosystem services? A pan-European, cross-taxa assessment. Front. Ecol. Environ. 8, 135-144

28 García-Berthou, E. et al. (2005) Introduction pathways and establishment rates of invasive aquatic species in Europe. Can. J. Fish. Aquat. Sci. 62, 453-463

29 Lavergne, S. and Molofsky, J. (2007) Increased genetic variation and evolutionary potential drive the success of an invasive grass. Proc. Natl. Acad. Sci. U.S.A. 104, 3883-3888 
30 Crooks, J.A. (2011) Lag times. In Encyclopedia of Biological Invasions (Simberloff, D. and Rejmánek, M., eds), pp. 404-410, University of California Press

31 Essl, F. et al. (2011) Socioeconomic legacy yields an invasion debt. Proc. Natl. Acad. Sci. U.S.A. 108, 203-207

32 Gassó, N. et al. (2010) Spreading to a limit: the time required for a neophyte to reach its maximum age. Divers. Distrib. 16, 310-311

33 Vitule, J.R.S. et al. (2009) Introduction of non-native freshwater fish can certainly be bad. Fish Fish. 10, 98-108

34 Simberloff, D. and Rejmánek, M., eds (2011) Encyclopedia of Biological Invasions, University of California Press

35 Vitousek, P.M. et al. (1987) Biological invasion by Myrica faya alters ecosystem development in Hawaii. Science 238, 802-804

36 Wardle, D.A. et al. (2011) Terrestrial ecosystem responses to species gains and losses. Science 332, 1273-1277

37 Bardgett, R.D. and Wardle, D.A. (2010) Aboveground-Belowground Interactions: Biotic Interactions, Ecosystem Properties and Global Change, Oxford University Press

38 Ordoñez, A. et al. (2010) Functional differences between native and alien species: a global-scale comparison. Funct. Ecol. 24, 1353-1361

39 Ehrenfeld, J.G. (2003) Effects of exotic plant invasions on soil nutrient cycling processes. Ecosystems 6, 503-523

40 Liao, C.Z. et al. (2008) Altered ecosystem carbon and nitrogen cycles by plant invasion: a meta-analysis. New Phytologist 117, 706-714

41 Simberloff, D. (2011) How common are invasion-induced ecosystem impacts? Biol. Invasions 13, 1255-1268

42 Vilà, M. et al. (2011) Ecological impacts of invasive alien plants: a meta-analysis of their effects on species, communities and ecosystems. Ecol. Lett. 14, 702-708

43 Rejmánek, M. and Pitcairn, M.J. (2002) When is eradication of exotic pest plants a realistic goal? In Turning the Tide: the Eradication of Invasive Species (Veitch, C.R. and Clout, M.N., eds), pp. 249-253, IUCN SSC Invasive Species Specialist Group

44 Gray, D.K. et al. (2007) Efficacy of open-ocean ballast water exchange as a means of preventing invertebrate invasions between freshwater ports. Limnol. Oceanogr. 52, 2386-2397

45 Roques, A. and Auger-Rozenberg, M-A. (2006) Tentative analysis of the interceptions of non-indigenous organisms in Europe 1995-2004. Bull. OEPP/EPPO Bull. 36, 490-496

46 Derraik, J.G.B. (2004) A survey of the mosquito (Diptera: Culicidae) fauna of the Auckland Zoological Park. N. Z. Entomol. 27, 51-55

47 Keller, R.P. et al. (2007) Risk assessment for invasive species produces net bioeconomic benefits. Proc. Natl. Acad. Sci. U.S.A. 104, 203-207

48 Jarrad, F.C. et al. (2011) Improved design method for biosecurity surveillance and early detection of non-indigenous rats. N. Z. J. Ecol. 35, 132-144

49 Kaiser, B.A. and Burnett, K.M. (2010) Spatial economic analysis of early detection and rapid response strategies for an invasive species. Resour. Energy Econ. 32, 566-585

50 Ficetola, G.F. et al. (2008) Species detection using environmental DNA from water samples. Biol. Lett. 4, 423-425

51 Chown, S. et al. (2008) DNA barcoding and the documentation of alien species establishment on sub-Antarctic Marion Island. Polar Biol. 31, 651-655

52 Harris, S. and Timmins, S.M. (2009) Estimating the Benefit of Early Control of all Newly Naturalised Plants (Science for Conservation: Vol. 292), New Zealand Department of Conservation

53 Caut, S. et al. (2009) Avoiding surprise effects on Surprise Island: alien species control in a multi-trophic level perspective. Biol. Invasions 11, 1689-1703

54 Genovesi, P. (2011) Are we turning the tide? Eradications in times of crisis: how the global community is responding to biological invasions. In Island Invasives: Eradication and Management (Veitch, C.R. et al., eds), pp. 5-8, IUCN

55 Panzacchi, M. et al. (2007) Population control of coypu Myocastor coypus in Italy compared to eradication in UK: a cost-benefit analysis. Wildl. Biol. 13, 159-171

56 McGeoch, M.A. et al. (2010) Global indicators of biological invasion: species numbers, biodiversity impact and policy responses. Divers. Distrib. 16, 95-108

57 Fine, J.M. and Sorensen, P.W. (2008) Isolation and biological activity of the multi-component sea lamprey migratory pheromone and new information in its potency. J. Chem. Ecol. 34, 1259-1267
58 Pala, C. (2008) Invasion biologists suck it up. Front. Ecol. Environ. 6, 63

59 Aldridge, D.C. et al. (2006) Microencapsulated BioBullets for the control of biofouling zebra mussels. Environ. Sci. Technol. 40, 975979

60 Martin, J.L. et al. (2000) Black rats, island characteristics and colonial nesting birds in the Mediterranean: current consequences of an ancient introduction. Conserv. Biol. 14, 1452-1466

61 Williamson, M. (1998) Measuring the impact of plant invaders in Britain. In Plant Invasions: Ecological Mechanisms and Human Responses (Starfinger, U. et al., eds), pp. 57-68, Backhuys Publishers

62 Gaertner, M. et al. (2012) Insights into invasion and restoration ecology: time to collaborate towards a holistic approach to tackle biological invasions. NeoBiota 12, 57-76

63 Golumbia, T. et al. (2008) History and current status of introduced vertebrates on Haida Gwaii. In Lessons from the Islands: Introduced Species and What They Tell Us About How Ecosystems Work (Gaston, A.J. et al., eds), pp. 8-31, Canadian Wildlife Service

64 Martin, J.L. et al. (2010) Top-down and bottom-up consequences of unchecked ungulate browsing on plant and animal diversity in temperate forests: lessons from a deer introduction. Biol. Invasions 12, 353-371

65 Hendrix, P.F. et al. (2008) Pandora's Box contained bait: the global problem of introduced earthworms. Annu. Rev. Ecol. Syst. 39 593-613

66 Sax, D.F. and Gaines, S.D. (2008) Species invasions and extinction: the future of native biodiversity on islands. Proc. Natl. Acad. Sci. U.S.A. 105, 11490-11497

67 Hobbs, R.J. et al. (2009) Novel ecosystems: implications for conservation and restoration. Trends Ecol. Evol. 24, 599-605

68 Mascaro, J. et al. (2012) Novel forests maintain ecosystem processes after the decline of native tree species. Ecol. Monogr. 82, 221-228

69 Nagel, T. (1961) The Structure of Science - Problems in the Logic of Scientific Explanation, Columbia University Press

70 Larson, B.M.H. (2011) Metaphors for Environmental Sustainability: Redefining Our Relationship with Nature, Yale University Press

71 Pauly, P.J. (1996) The beauty and menace of the Japanese cherry trees: conflicting visions of American ecological independence. Isis 87, 51-73

72 Perry, D. and Perry, G. (2008) Improving interactions between animal rights groups and conservation biologists. Conserv. Biol. 22, 27-35

73 Council of Europe (2000) Declaration on Cultural Diversity, Council of Europe

74 UNESCO (2001) UNESCO Universal Declaration on Cultural Diversity, UNESCO

75 Born, W. et al. (2005) Economic evaluation of biological invasions: a survey. Ecol. Econ. 55, 321-336

76 Villéger, S. et al. (2011) Homogenization patterns of the world's freshwater fish faunas. Proc. Natl. Acad. Sci. U.S.A. 108, 1800318008

77 Lambertini, M. et al. (2011) Invasives: a major conservation threat. Science 6041, 404-405

78 Callicott, J.B. (1980) Animal Liberation: a triangular affair. Environ. Ethics 4, 311-338

79 Maris, V. and Béchet, A. (2010) From adaptive management to adjustive management: a pragmatic account of biodiversity values. Conserv. Biol. 24, 966-973

80 MacDougall, A.S. and Turkington, R. (2005) Are invasive species the drivers or passengers of change in degraded ecosystems? Ecology 86 42-55

81 Martin, P.H. et al. (2009) Why forests appear resistant to exotic plant invasions: intentional introductions, stand dynamics, and the role of shade tolerance. Front. Ecol. Environ. 7, 142-149

82 Simberloff, D. (2009) The role of propagule pressure in biological invasions. Annu. Rev. Ecol. Evol. Syst. 40, 81-102

83 Lovett, G.M. et al. (2006) Forest ecosystem responses to exotic pests and pathogens in eastern North America. BioScience 56 , 395-405

84 Wardle, D.A. et al. (2001) Impacts of introduced browsing mammals in New Zealand forests on decomposer communities, soil biodiversity and ecosystem properties. Ecol. Monogr. 71, 587-614

85 Anderson, C.B. et al. (2006) The effects of invasive North American beavers on riparian plant communities in Cape Horn, Chile: do exotic 
beavers engineer differently in sub-Antarctic ecosystems? Biol. Conserv. 128, 467-474

86 Sala, E. et al. (2011) Alien marine fishes deplete algal biomass in the eastern Mediterranean. PLoS ONE 6, e17356

87 O’Dowd, D.J. and Green, P.T. (2010) Invasional meltdown: do invasive ants facilitate secondary invasions? In Ant Ecology (Lach, L. et al., eds), pp. 271-272, Oxford University Press

88 Fukami, T. et al. (2006) Above- and below-ground impacts of introduced predators in seabird-dominated island ecosystems. Ecol. Lett. 9, 1299-1307

89 Croll, D.A. et al. (2005) Introduced predators transform subarctic islands from grassland to tundra. Science 307, 1959-1961

90 Baxter, C.V. et al. (2004) Fish invasion restructures stream and forest food webs by interrupting reciprocal prey subsidies. Ecology 85, 2656-2663

91 Pringle, R.M. (2011) Nile Perch. In Encyclopedia of Biological Invasions (Simberloff, D. and Rejmánek, M., eds), p. 484, University of California Press

92 Loo, J.A. (2009) Ecological impacts of non-indigenous invasive fungi as forest pathogens. Biol. Invasions 11, 81-96
93 Boag, B. and Neilson, R. (2006) Impact of New Zealand flatworm on agriculture and wildlife in Scotland. Proc. Crop Prot. Northern Br. 2006, 51-55

94 Sousa, R. et al. (2009) Non-indigenous invasive bivalves as ecosystem engineers. Biol. Invasions 11, 2367-2385

95 Talley, T.S. et al. (2001) Habitat utilization and alteration by the burrowing isopod, Sphaeroma quoyanum, in California salt marshes. Mar. Biol. 138, 561-573

96 Woodfield, R. et al. (2006) Final Report on the Eradication of the Invasive Seaweed Caulerpa taxifolia from Agua Hedionda Lagoon and Huntington Harbour, California, Southern California Caulerpa Action Team

97 Meinesz, A. (2001) Killer Algae, University of Chicago Press

98 Boyer, A. (2008) Extinction patterns in the avifauna of the Hawaiian islands. Divers. Distrib. 14, 509-517

99 Rodriguez-Cabal, M.A. et al. (in press) The establishment success of non-native birds in Hawaii and Britain. Biol. Invasions

100 Apostol, D. and Shlisky, A. (2012) Restoring temperate forests, a North American perspective, In Restoration Ecology: The New Frontier (2nd edn) (Van Andel, J. and Aronson, J., eds), pp. 161172, Wiley-Blackwell 